\title{
LA EVOLUCIÓN MATERIAL Y ENERGÉTICA DE LOS EEUU, 1980- 2010
}

\section{A EVOLUÇÃO MATERIAL E ENERGÉTICA DOS EUA, 1980-2010}

\author{
Vitor Eduardo Schincariol ${ }^{\star}$
}

\begin{abstract}
"In the present landscape we can detect only two opposing elements, reversible locomotion and irreversible entropy".

Nicholas Georgescu-Roegen. The Entropy Law and the Economic Process, 1971.
\end{abstract}

\begin{abstract}
Resumen: Este artículo analiza la evolución de algunos datos materiales y energéticos referentes a la economía de los Estados Unidos, en el período entre 1980 y 2010. Se demuestra que, a pesar de la economía norteamericana haber evidenciado una gran elevación de su productividad energética por unidad de PBI (Producto Bruto Interno) a lo largo de los años 1980-2010, no logró elevar la productividad ni energética ni material por habitante para tal periodo. La conclusión es que su modelo de desarrollo encontrará obstáculos en el futuro en lo que se refiere a la existencia material de su base industrial, particularmente la escasez de combustibles fósiles como el crudo.
\end{abstract}

Palabras clave: historia ambiental; condiciones energéticas; lei de entropía; recursos naturales; historia económica y ambiental de los Estados Unidos.

Resumo: O artigo analisa a evolução de dados materiais e energéticos referentes à economia dos Estados Unidos, entre o período 1980 e 2010. Apesar de ter a economia norte-americana sofrido uma elevação da produtividade energética por unidade de PIB (Produto Interno Bruto) ao longo do período mencionado, não mostrou um aumento da produtividade energética nem material por habitante ao longo do tempo. A conclusão é que seu modelo de desenvolvimento encontrará obstáculos no futuro, no que se refere à existência material de sua base industrial, particularmente a escassez de combustíveis fósseis como o petróleo.

Palavras-chave: história ambiental; condições energéticas; lei de entropia; recursos naturais; história econômica e ambiental dos Estados Unidos.

\section{Debate}

El presidente de los EEUU y sus asesores económicos, en uno de los principales documentos oficiales referentes a el estado de la economía en 2010, Economic Report of the President, tienen el cuidado de, al mencionar el problema ambiental, referirse apenas a la cuestión energética, y no a las materias primas propiamente dichas. Esto no es sin razón: hoy hay fuentes alternativas de energía que, aun siendo una parte muy pequeña de las fuentes energéticas totales de la economía del país, como se verá abajo, pueden - en teoría - substituir las actuales fuentes de energía hoy disponibles. Pero no pasa lo mismo con todas las materias primas, que no pueden ser creadas, solamente recicladas. Así, el capítulo referente a el

\footnotetext{
* Professor Adjunto da Faculdade de Administração, Economia e Contabilidade da Universidade Federal de Alagoas. Doutor em História Econômica pela Universidade de São Paulo.
} 
problema ambiental, el capítulo seis, se llama "Transition to a clean energy future", y no "Transition to a clean future".

\begin{abstract}
"American prosperity depends on a continuous supply of safe and reliable energy. energy heats, cools, and lights homes and businesses; transports workers to jobs, customers to stores, and families to relatives; and runs the factories that manufacture the goods Americans consume and export. It is increasingly clear, however, that existing energy supplies pose risks to national security, the environment, the climate, and the economy. To counter those risks, while recognizing the continued importance of safe, responsible oil and gas production to the economy, the Administration is committed to moving the Nation toward use of cleaner sources of energy with the potential to support new industries, exports, and high-quality jobs; to improve air quality and protect the climate; and to enhance America's energy security and international competitiveness." 1
\end{abstract}

En la introducción del documento, el presidente Obama afirma, a la página 3, con relación a las políticas para combatir la crisis:

"The most immediate task must be to get our fellow Americans back to work by accelerating economic growth and job creation by the private sector."

La teoria económica de inspiración neoclásica, por ejemplo en los trabajos de Robert Solow, discute la escasez de los recursos naturales como un problema de "substitución". La escasez de un determinado material escaso puede ser solucionada con el incremento tecnológico, mediante la creación de otro nuevo, reproducible. En un conocido texto, Robert Solow afirmó:

\begin{abstract}
"It is clear without any technical apparatus that the seriousness of the resourcesexhaustion problem must depend in an important way on two aspects of the technology: first, the likelihood of technical progress, especially natural-resource-saving technical progress, and, second, the ease with which other factors of production, especially labor and reproducible capital, can be substituted for exhaustible resources in production. [...] Fortunately, what little evidence there is suggests that there is quite a lot of substitutability between exhaustible resources and renewable or reproducible resources, though this is an empirical question that could absorb a lot more work than it has so far." 2
\end{abstract}

La teoria ambientalista inspirada en los trabajos de Georgescu-Roegen aborda el problema más profundamente. La actuación de la llamada "Ley de la Entropía", según Georgescu, impide una substitución entre factores de producción, porque todos los bienes económicos están bajo el proceso irreversible del "aumento del grado de entropía a lo largo del

\footnotetext{
1 Gobierno de los Estados Unidos, Economic Report of the President 2010. Washington: U.S. Government Printing Office, 2011, p. 125.

2 Robert Solow, "The Economics of Resources or the Resources of Economics". The American Economic Review, v. 64, n.2, Mayo de 1974, p. 11.
} 
tiempo". Esto quiere decir que, según Georgescu, la actividad económica no puede contar con futuras substituciones de un material o técnica por otra porque, con la elevación de la acumulación de capital y los desgastes naturales de todos los tipos de materiales naturales disponibles, todas las fuentes materiales van escasear. No existiría manera de creación de sustitutos en un realidad con escasez para todas las fuentes de materias primas. Donde surgirían las materias primas para sustituir y mismo para construir las máquinas y aparatos productivos si los desgastes son generales?

Comentando la segunda Ley de la Entropía, Georgescu afirma:

"If it were possible to, say, to burn the same piece of coal over and over again ad infinitum, or if any piece of metal lasted forever, then the low entropy would belong to the same economic category of land. [...] Production represents a deficit in entropy terms: it increases total entropy by a greater amount than that which would result from the automatic shuffling in the absence of any productive activity. Indeed, it seems unreasonable to admit that our burning a piece of coal does not mean a speedier diffusion of its free energy than if the same coal were left to its own fate." 3

Hay un debate teórico entre las dos perspectivas. Los trabajos de Georgescu tienen un punto de vista muy pesimista cuanto al futuro de las sociedades basadas en la lógica capitalista actual. Las sugestiones que hace en diversos textos claramente apuntan para un cámbio en el patrón de acumulación.

Igualmente, la perspectiva de que la manutención de un alto patrón de inversiones privadas de tipo capitalista no son la manera global más adecuada para gestionar la escasez material y los problemas ambientales es defendida por muchas otras perspectivas teóricas, como la pos-keynesiana y la marxista.

Michael Löwy es uno de los representantes del marxismo que busca argumentar que el problema ambiental no puede ser solucionado dentro de un paradigma capitalista. En el texto "Écosocialisme et plannification democratique", afirma este autor a la página 2 :

"Selon les écosocialistes, le problème des principaux courants de l'écologie politique, dont les représentants sont les partis verts, est qu'ils ne semblent pas prendre en considération la contradiction intrinsèque qui existe entre la dynamique capitaliste fondée sur l'expansion illimitée du capital et l'accumulation des profits - et la préservation de l'environnement. II en découle une critique du productivisme souvent pertinente, mais qui ne mène pas pour autant plus loin que les reformes écologiques dérivées de 'l'économie de marché'." 4

Joan Robinson, por su parte, afirmaba:

\footnotetext{
${ }^{3}$ N. Georgescu-Roegen, The Entropy Law and the Economic Process. New York: Harvard University Press, 1971, p. 278-279.

4 Disponible en www.lafederation.org /.
} 


\begin{abstract}
"The problem of the use of resources, and the institutional setting that controls it, cannot be confined within the bounds of theoretical economic analysis, but the economic aspect of matter ought to be discussed. What is the objective of production in a modern industrial nation, and if we could have more of it (through technical change and capital accumulation), what should we use it for? For the classical economists, such a question not arise. The wealth of a nation was its investable surplus; real wages were part of the cost of production, like fodder for cattle, and luxury consumption was deprecated; the neoclassicists conceived the objective of production to be the provision of consumption. But consumption by whom, for what? The question was supposed to be settled by appeal to the individual's free of choice, but there are three very large objections to such a solution." 5
\end{abstract}

Las objeciones para una resolución con base en consumo individual serian, para la autora: el poder económico es muy mal distribuido; muchos tipos de consumo individuales tienen desutilidad para la colectividad; es necesario introducir siempre nuevos productos para mantenerla acumulación de tipo capitalista; las decisiones sobre qué y cómo consumir son determinadas por las grandes empresas, y no por la opinión popular.

Este debate puede ser de a poco solucionado por la pesquisa teórica y empírica. En este texto, investigamos un problema delimitado, cuya aclaración permite hacer algunas sugestiones sobre el debate mencionado. El problema a investigar es la trayectoria del consumo de materias primas y energía en los Estados Unidos a lo largo de su historia reciente (1980-2010). Particularmente, el objetivo es analizar las tendencias de las reservas, consumo e importación de los principales bienes naturales en los Estados Unidos, incluidos ahí las fuentes de energía, e investigar igualmente la trayectoria del consumo energético y material por el PBI y por habitante durante el tiempo. Después del análisis, el texto hace algunas sugestiones relativas al debate al cual se hizo referencia arriba.

\title{
Desempeño material y energético
}

Vamos a empezar con el análisis del consumo final de energía; más particularmente, con su relación con el PBI y el número de habitantes en los Estados Unidos. El consumo final de energía hace referencia a la cantidad de energía utilizada para producción y consumo en un periodo de tiempo. Energía es solamente una parte del acervo material social. La otra parte es el acervo de bienes y materiales utilizados para consumo o construcción de capital fijo y circulante. Pero aun asi conserva importancia crucial.

Veamos primeramente cual es la relación entre el consumo de energía final y el PBI en los Estados Unidos. Abajo, sigue el gráfico que muestra tal relación. La construcción está hecha

\footnotetext{
5 Joan Robinson, Further Contributions to Economic Analysis. Oxford: Basil Blackwell, 1980, p. 31.
} 
por la división entre el consumo final de energía en el país, expresadas en Btu (British Termal Unity), y el PBI, expresado en dólares.

Gráfico 1. EEUU. Relación entre el consumo final de energía (fósiles, nucleares y renovables) y el Producto Bruto Interno. 1965-2009. Energía en quadrillones de Btu (British Termal Unity), donde $1 \mathrm{Btu}=252,2$ calorías, y Producto Bruto Interno en Billones de dólares. *

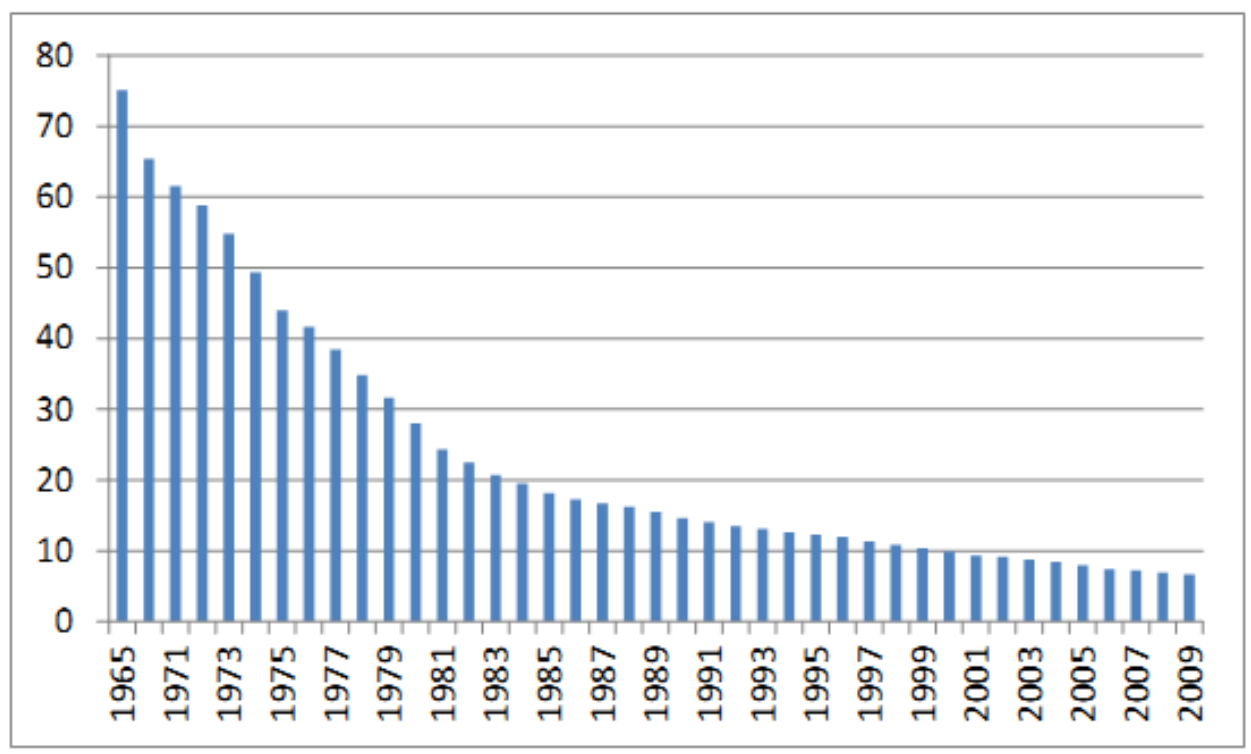

Fuente: datos de U.S. Energy Information Administration - Annual Energy Review, 2009, p.5 (www.eia.gov/aer) y BEA. * La escala vertical del gráfico se explica de la siguiente forma: para el año de 1965, por ejemplo, 54.017 cuadrillones (Btu) consumidos son divididos por um PBI de 719.1 billones de dólares.

El perfil de la división es claramente decreciente. O sea, la economía de los EEUU parece estar creciendo cada vez más con menos utilización de energía. ¿Cómo se explicaría esta relación aparentemente muy positiva? La relación es importante y suscita diversas interpretaciones.

Primeramente, es necesario reconocer que la gran parte de los bienes de utilización final y los bienes de capital son más productivos en términos energéticos a lo largo del tiempo. Es decir, el menor consumo individual por bien de energía eléctrica, de crudo, de gas, y otros, es producto de la evolución de las técnicas de fabricación en la industria moderna. Con lo cual, los autos, las teles, las lámparas, las computadoras, así como la mayoría de los productos de consumo final, consumen menos cantidad de energía individualmente en 2000 que en 1965. La competencia capitalista lleva naturalmente a mejorías en la productividad energética de los bienes. Como el consumo final cuenta con más de $75 \%$ del PBI estadunidense, el menor 
consumo energético individual de los bienes es factor explicativo importante de la caída del uso de energía por unidad de PBI. 6

Un segunda razón importante que explica la disminución de la relación entre el PBI y el uso de energía a lo largo del tiempo es la relación de las finanzas y otras actividades no relativas a la "economía real" en el PBI. En una época de crecimiento de la participación de las finanzas en el PBI cada vez mayor, es difícil distinguir la producción y el consumo "real" de los números financieros, cuya relación con la economía "real" tenga impacto en la producción de energía. 0 sea, el PBI estadunidense es mayor a lo largo del tiempo en términos numéricos, pero buena parte de este crecimiento es referente a una mayor participación del giro financiero en la economía, incluso con la participación de las finanzas extranjeras en la economía. (No se puede olvidar que los EEUU se tornaran los mayores deudores externos contemporáneos entre todos los países del capitalismo mundial.)

Así, las finanzas representaban 393 mil millones de dólares en 1979 y 3.040 mil millones en 2009, para PBl's respectivos de 5.855 y 12.880 mil millones - crecimiento relativo de $12 \%$ para $23 \%$ del PBI. Con lo cual, no se podría afirmar que todo el PBI estadunidense esté traducido en consumo e inversión en una situación donde las finanzas conforman $23 \%$ del $\mathrm{PBI}$ (2009). Así, un análisis más real tendría que rever la relación aparentemente tan favorable entre $\mathrm{PBI}$ y energía consumida.

Una tercera explicación seria la propia tasa de inflación, porque acá usamos los valores corrientes de PBI en dólar.

Por otro lado, los números del informe de 2009 de la U.S. Energy Information Administration sobre las condiciones energéticas en los Estados Unidos muestran otra relación cuando se compara el consumo de energía final en el país y el número de habitantes. Esta relación está expresada en el gráfico de abajo, con datos de población fornecidos por Economic Report of the President de 2010.

\footnotetext{
${ }^{6}$ Aproximadamente $75 \%$ en 2009 , de acuerdo con el Economic Report of the President de 2010, p.190.
} 
Gráfico 2. EEUU. Relación entre el consumo final de energía en los Estados Unidos (fósiles, nucleares y renovables) y el número de habitantes. 1965-2009. Energía en quadrillones de Btu (British Termal Unity), donde $1 \mathrm{Btu}=252,2$ calorías y población en millones. *

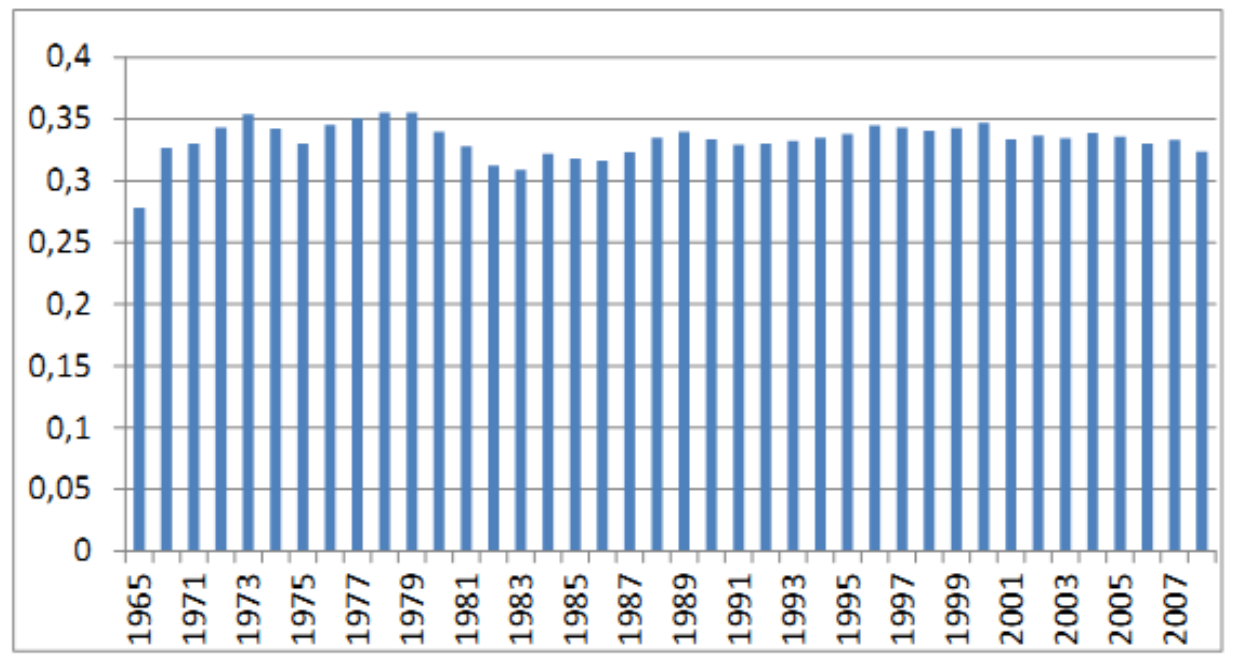

Fuente: U.S. Energy Information Administration - Annual Energy Review, 2009, y BEA. * La escala vertical del gráfico se explica de la siguiente forma: para el año de 1965, por ejemplo, 54.017 cuadrillones (Btu) consumidos son divididos por 194.303 millones de personas.

El gráfico muestra un desempeño energético distinto, según el parámetro energía/habitante. Entre 1965 y 2008, la relación entre el consumo final de energía y el número de habitantes es, de hecho, bastante constante. ¿Pero por qué?

Esto se puede atribuir primeramente a una mayor utilización de bienes per capita, hecho natural de una economía industrial que baratea a lo largo del tiempo los precios monetarios de las mercancías de utilización final, particularmente los bienes electrónicos. Hay una mayor utilización absoluta de bienes por individuo, con lo cual lo que se gana en eficiencia energética se pierde con una mayor utilización absoluta de bienes. Esta relación, más "real", por comparar dos datos mucho más precisos - energía en Btu y población en millones de personas - es mucho más útil que la primera relación arriba comentada para evaluar la tendencia "energética" de la economía.

Continuando con el análisis de los datos de energía, pasemos a otros datos del informe de U.S. Energy Information Administration en 2009. Estos son muy ilustrativos de las tendencias en la utilización globales. Abajo siguen dos imágenes con diversos gráficos. 


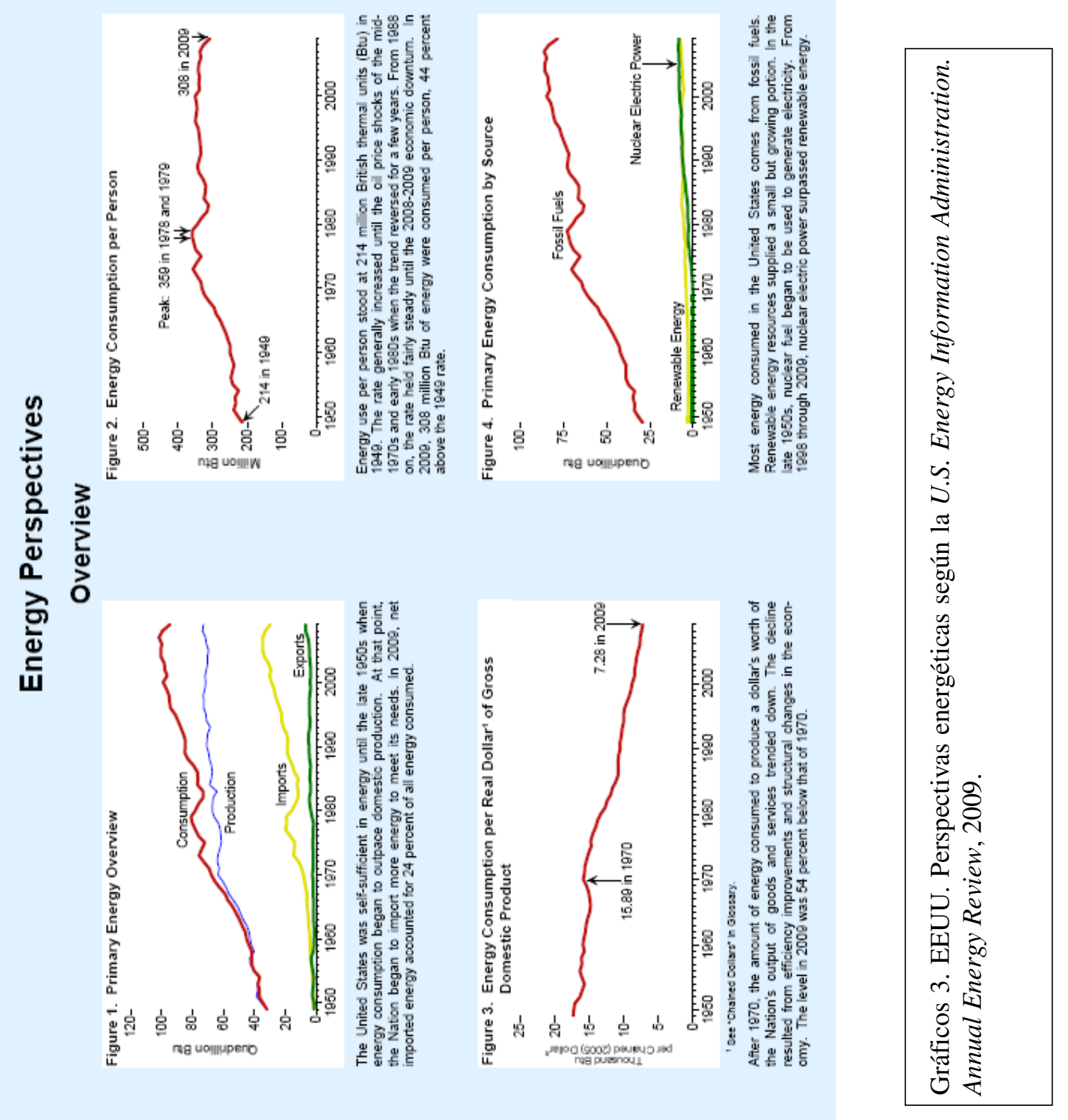




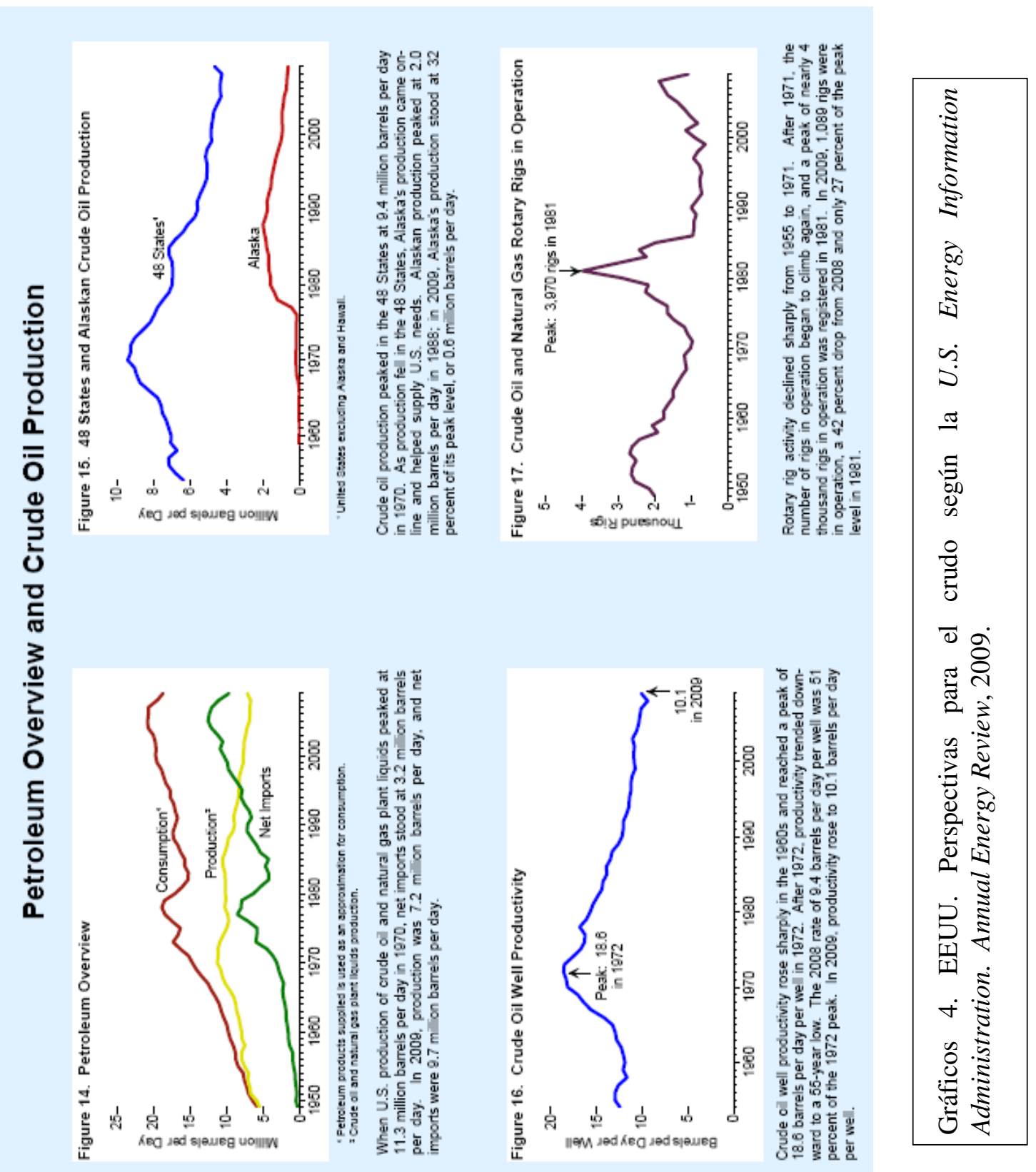

Primeramente, uno puede notar que los EEUU están importando cada vez más energía (Figure 1). Hay un déficit creciente entre su consumo interno y su producción. Los combustibles fósiles son los principales utilizados en el país, con participación relativa creciente y mayor que los renovables (Figure 4). Particularmente, las figuras denotan una enorme distancia entre las utilizaciones de fósiles y otras formas de energía.

Al mismo tiempo, el relatorio muestra cómo la producción interna de crudo en los EEUU está declinando al mismo tiempo en que las importaciones están elevándose (Figure 14). Esto deja ver, con mucha claridad, que los Estados Unidos están ahorrando crudo internamente y utilizando los stocks mundiales. En el futuro, la autonomía material del país estará más 
asegurada que los actuales exportadores, cuyas reservas estarán crecientemente agotadas. Igualmente significativa es la decreciente productividad de los pozos de crudo (figure 16, segundo grupo de gráficos transcriptos). A partir de las figuras se pueden observar también las relaciones arriba comentadas, con relación al uso de energía estable por individuo (Figure 2) y por PBI (Figure 3). La producción de combustibles para autos es el principal destino de la producción de petróleo en el país, con una utilización casi cuatro veces mayor que la propia utilización para fines industriales.

Hay muchos más datos importantes en este extenso trabajo. ${ }^{7}$ Podemos comentar algunos más sin transcribirlos integralmente, invitando al lector a que lea él mismo el informe. Por ejemplo, la productividad en la extracción de carbón, después de un enorme crecimiento de entre 1980 y 2000, empieza a declinar a partir de este año, con un fuerte choque para abajo sin interrupción hasta la fecha (2011). La producción de superficie crece y la de subsuelo cae. La construcción de nuevas usinas nucleares se encuentra estancada, con 112 unidades en 2004 y 104 en 2009. La energía de tipo renovable también crece, pero su participación en el total no llega a 10 quadrillones de Btu, al paso que la utilización energética de fósiles es mayor que 50 quadrillones de Btu anuales. Un 55\% de la energía norteamericana provienen de carbón, crudo y gas.

Por ende, abajo se pueden ver las cantidades de reservas probadas de crudo en los EEUU, bien como una estimativa con base en la tendencia. La tendencia decreciente conocida se extiende de 1970 a 2011, y puede, en teoria, ser modificada por el hallazgo de nuevas reservas aún no conocidas o divulgadas. Sea como sea, puede notarse una dependencia cada vez mayor del crudo internacional por parte de los Estados Unidos, después que sus propias reservas estén agotadas. Hay ahí una tendencia doble entre el mayor consumo doméstico con importaciones y el ahorro interno de las propias reservas. La política externa norteamericana, por lo que vemos a partir de su comportamiento en el Medio Oriente hoy, va elevar sus intervenciones militares para asegurar el abastecimiento de crudo, al mismo tiempo que el aumento del consumo interno tendrá que forzar la utilización del crudo local, contrariamente al panorama actual.

\footnotetext{
${ }^{7}$ Para el informe mencionado, ver www.eia.gov/aer $/$.
} 
Gráfico 5. EEUU. Reservas probadas de crudo en los Estados Unidos (Millones de Barriles) y tendencia futura estimada a partir de la conocida hasta 2011.

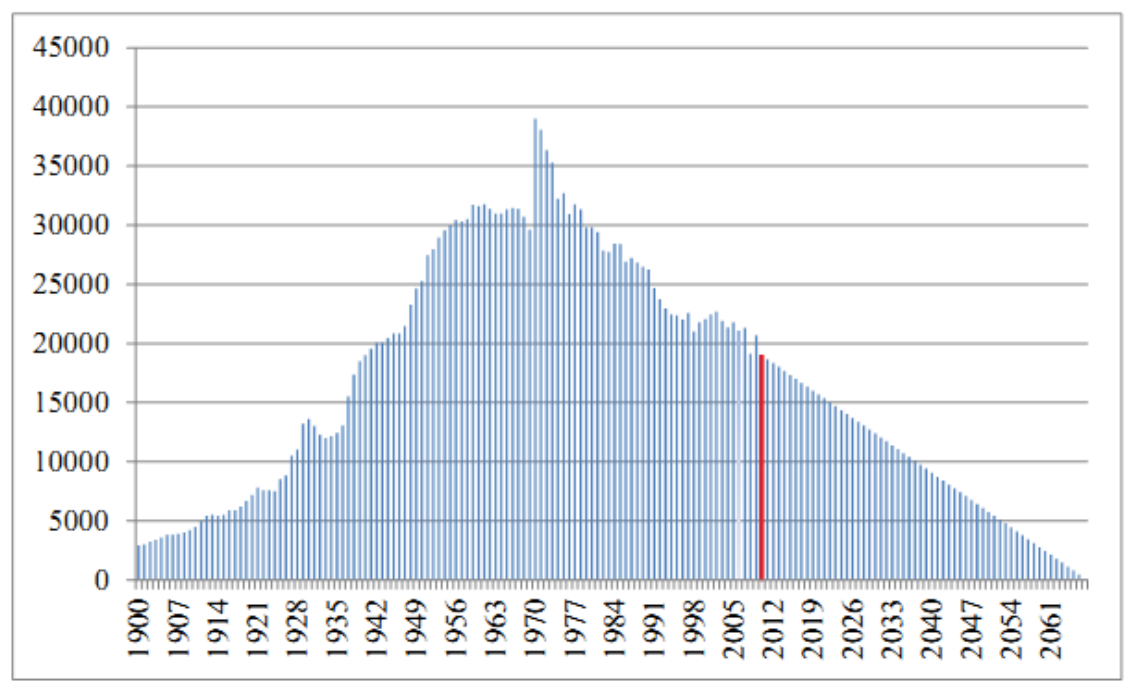

Fuente: Agencia Internacional de Energía. Obs.: la tendencia futura hasta 2067 está calculada a partir de la tendencia observada entre 1970 y 2011.

Los Estados Unidos, hasta acá, están entonces bastante sujetos a las dificultades que devienen de la Ley de la Entropía. La mayor parte de sus fuentes de energía actuales provienen de materias primas que no pueden ser reutilizadas. Ahora vamos a utilizar algunos otros datos referentes a los recursos materiales de forma más global, no exclusivamente energéticos.

Abajo está una figura producida en el documento "Materials and the Economy, Material Flows, Scarctiy, and the Environment”, un informe disponible en el sitio de U.S. Geological Survey. ${ }^{8}$ Los datos son significativos. La figura muestra el porcentaje de materiales no renovables (no renewable) en la utilización total estadunidense entre 1900 y 2000. Los bienes no renovables se elevan hasta $90 \%$ del total, cuando en 1900 no conformaban más que el $60 \%$. La economía estadunidense ha usado de modo menos "sostenible" sus recursos internos con el pasar del tiempo. Esto no es extraño, porque para que los recursos no agotables sean más utilizados hay casi siempre que invertir en un aparato de reciclaje, al paso que la utilización de los no renovables no exige tales inversiones.

\footnotetext{
8 Ver http://minerals.usgs.gov/minerals/mflow/ .
} 
Gráfico 6. EEUU. Porcentajes de bienes renovables y no renovables en el total de materiales utilizados en una base por peso (per-weight basis).

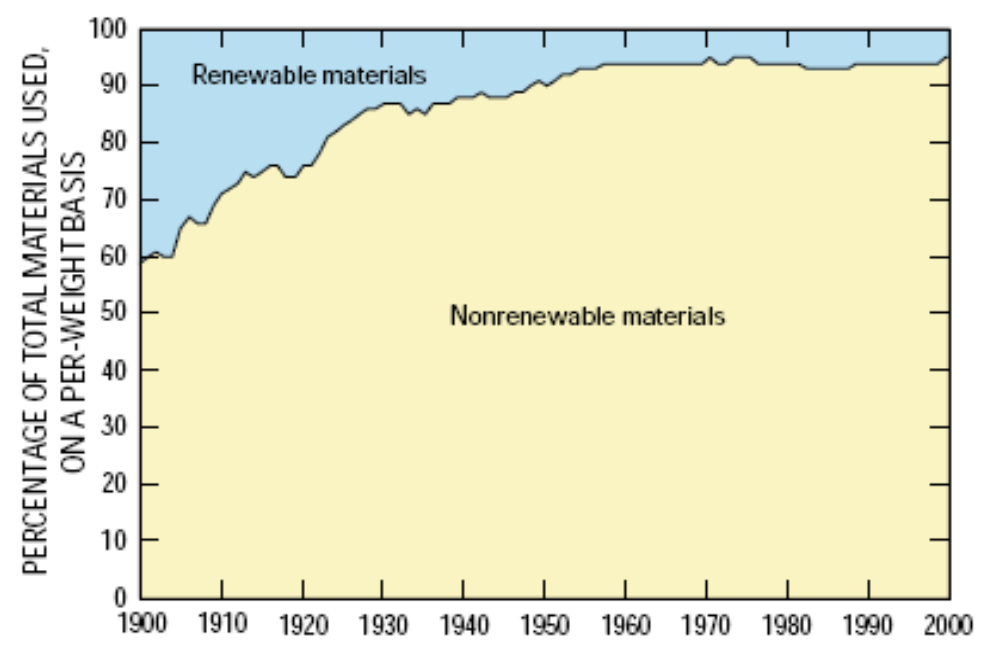

Fuente: Informe "Materials and the Economy, Material Flows, Scarctiy, and the Environment", U.S. Geological Survey.

El gráfico de abajo es igualmente interesante. El muestra la cantidad de algunas materias primas consumidas en la economía estadunidense a lo largo del siglo XX. La cantidad de piedras, arena y gija (stone, sand and gravel, como se ve na figura) crece de forma particularmente grandiosa, en toneladas - aproximadamente 30 veces entre 1900 y 2000. Los minerales industriales muestran crecimiento particularmente grande, igualmente, llegando a 500 millones de toneladas anuales a partir de 2000. Prácticamente todas las fuentes disponibles de materias primas en este país pasaron por un crecimiento vigoroso entre 1900 y 2000. Las disminuciones en la utilización se dan justamente en las fluctuaciones negativas del PBI, como en la crisis de 1929, la crisis de los setenta, la recesión de los ochenta, del inicio de los noventa, y, se puede imaginar, durante la actual crisis (2008-2011). Hay así una gran elasticidad del consumo de materias primas con relación al crecimiento del PBI, pero cuando la economía se recupera el crecimiento del consumo absoluto vuelve a darse. 
Gráfico 7. EEUU. Flujo (row) de materias primas (raw materials) en los EEUU, en millones de toneladas cúbicas anuales.

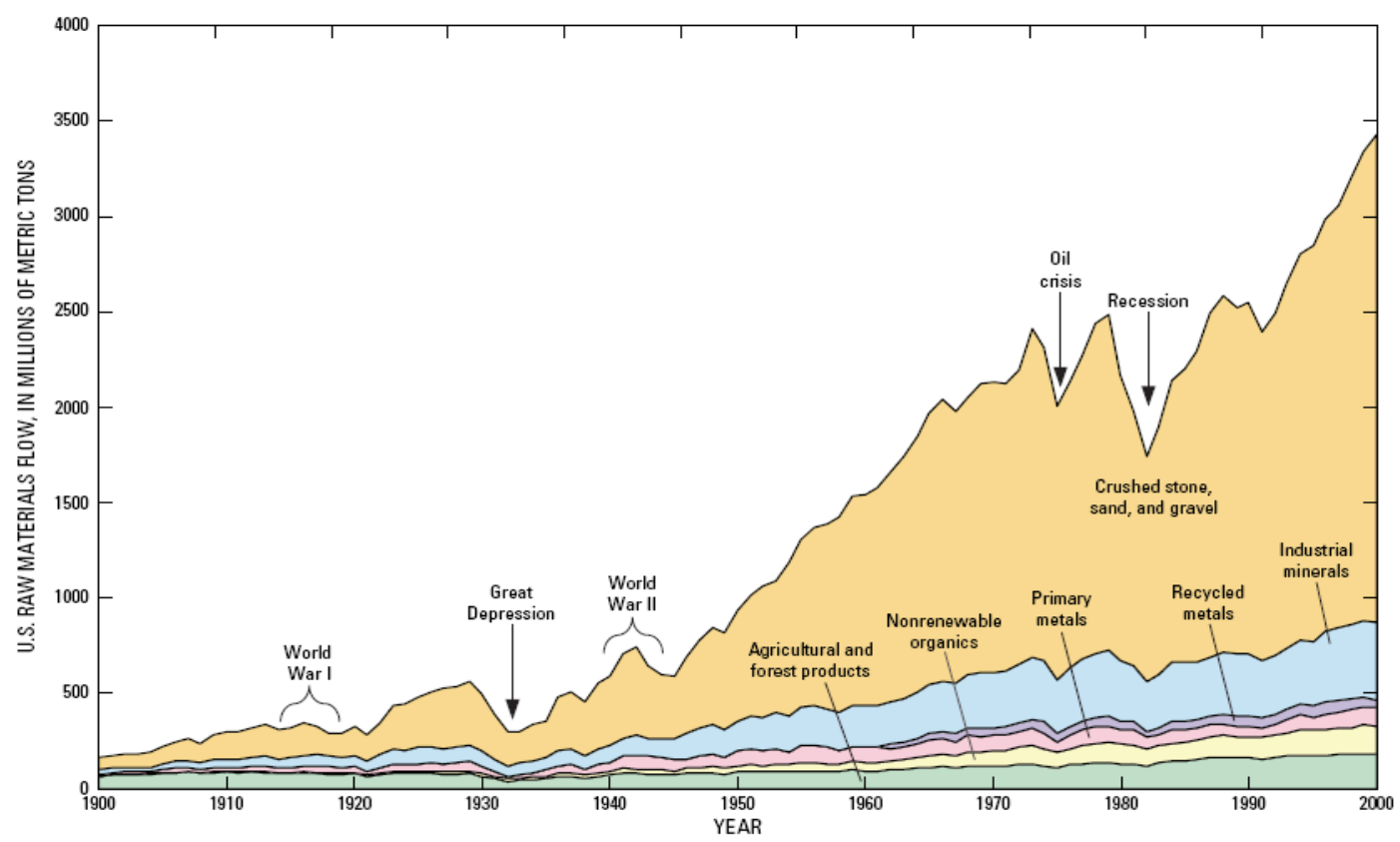

Fuente: Informe "Materials and the Economy, Material Flows, Scarctiy, and the Environment", de U.S. Geological Survey.

El U.S. Geological Survey presenta muchos otros datos relevantes (recordando que su sitio es http://www.usgs.gov). Abajo vamos a comentar el perfil de consumo, stocks e importación de algunos minerales importantes a partir de los datos del sitio Historical Statistics for Mineral and Material Commodities in the United States producido por la propia U.S. Geological Survey. ${ }^{9}$

Primeramente, el carbón. No hay informaciones sobre importaciones ni stocks. El perfil de producción es creciente, con una pequeña caída para 2008 y 2009, como efecto de la crisis económica. Este crecimiento más o menos constante de la producción, leída en conjunto para la mayoría de los otros materiales analizados, es un importante dato para contestar la tesis de la "desmaterialización" de la economía, así como la tesis de que la "inter-sustitución" o el progreso técnico pueden evitar la Ley de Entropía.

\footnotetext{
9 Ver http://minerals.usgs.gov/ds/2005/140/.
} 
Gráfico 8. EEUU. Producción de carbón, en millones de toneladas cúbicas anuales. 1966-2009.

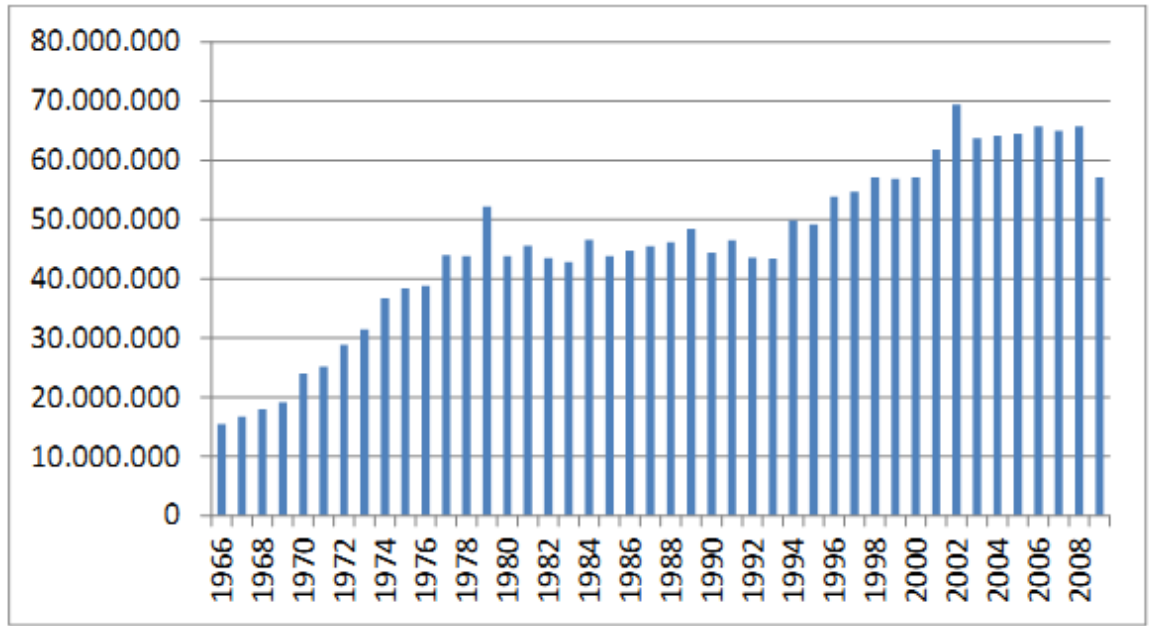

Fuente: U.S. Geological Survey.

La producción de minería de hierro es una en la cual la actuación de la Ley de Entropía es más presente. Desde los años (19)70 los stocks presentan disminución, mientras la producción va elevándose. Este trayecto es distinto del referente al pasado, cuando producción y stocks se elevan juntos. Es decir, producción y nuevas descubiertas caminaran juntos por setenta años y después se separaran. Para mantener la utilización constante, las importaciones necesariamente se elevarán.

Gráfico 9. EEUU. Producción y stocks de minería de hierro, en millones de toneladas cúbicas anuales. 19002009.

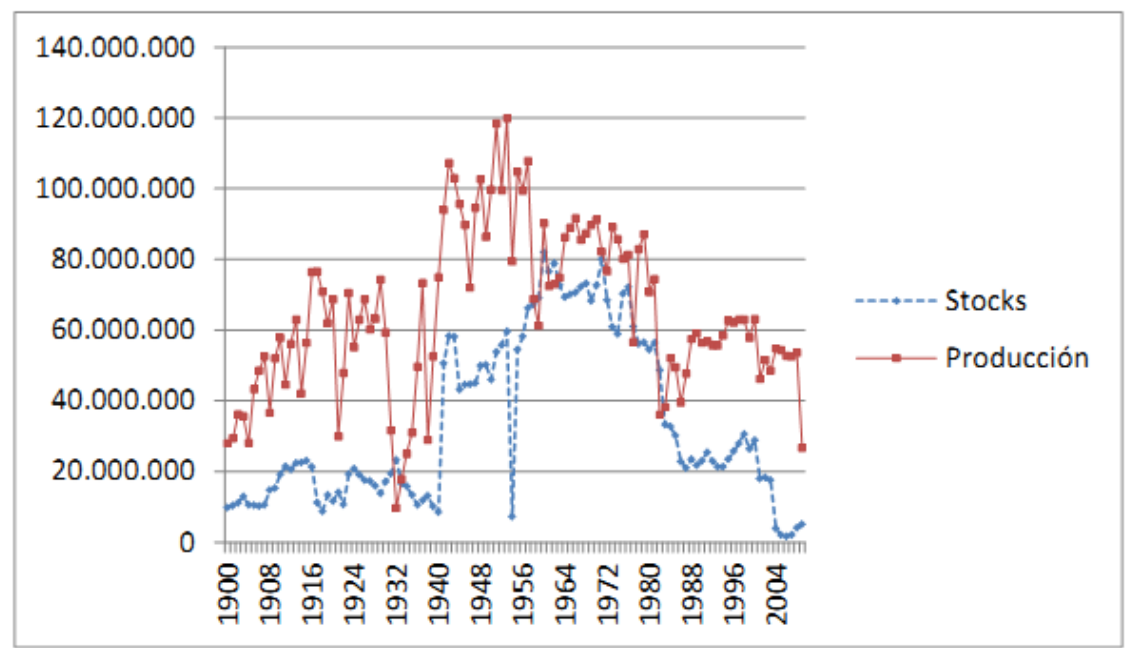

Fuente: U.S. Geological Survey. 
Con níquel la situación de los stocks y producción es particularmente discrepante con la utilización. A pesar de una disminución de las importaciones a partir de los (19)70, mostrando mayor productividad media en la utilización, la utilización doméstica se eleva, mientras la producción interna y los stocks van en caída constante. El interese de este y otros gráficos es mostrar la situación decreciente de los stocks en el país con el pasar del tiempo. Aumentará la necesidad de mayor inversión en reciclaje e importación.

Gráfico 10. EEUU. Producción y stocks de níquel, en millones de toneladas cúbicas anuales. 1900-2009.

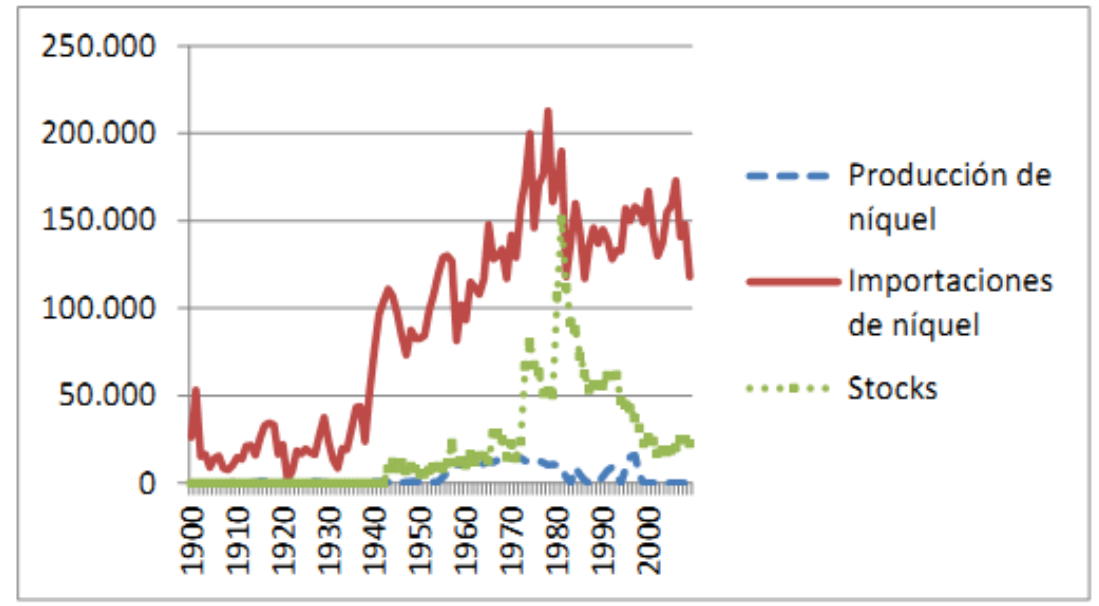

Fuente: U.S. Geological Survey.

Abajo se ve el gráfico con datos de producción, stocks e importación de cobre.

Gráfico 11. EEUU. Producción y stocks de cobre, en millones de toneladas cúbicas anuales. 1900-2009.

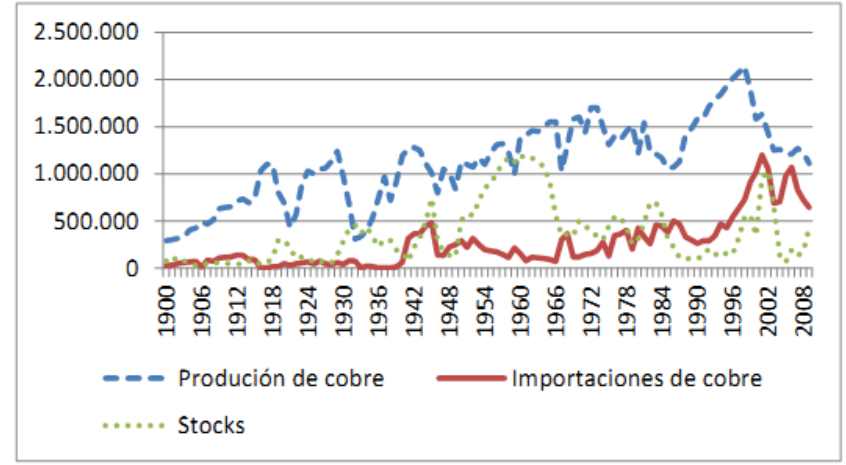

Fuente: U.S. Geological Survey.

Con cobre, hay crecimiento constante de la producción, crecimiento paralelo de las importaciones y caída constante de los stocks. Los stocks se elevan en meados de la década de 
(19)90, pero no hubo nuevos descobrimientos que hicieran con que la cantidad total se mantuviese en crecimiento constante. Los stocks van cayendo a medida que las importaciones se elevan, una vez más mostrando como las reservas domésticas disminuyen y la dependencia de importaciones de materias primas se incrementa.

La enorme cantidad de datos minerales para los Estados Unidos está ahí para ser investigada con más tiempo. La investigación indicará este patrón constante: agotamiento progresivo de stocks con elevación de las importaciones. Cobalto es otro ejemplo de este patrón común, con la excepción de que la producción interna se terminó en los (19)70. Después de 1985 los stocks presentan disminución sin interrupción y las importaciones tienen, por lo tanto, que crecer.

Gráfico 12. EEUU. Producción primaria, secundaria, stocks e importaciones de cobalto, en millones de toneladas cúbicas anuales. 1940-2009.

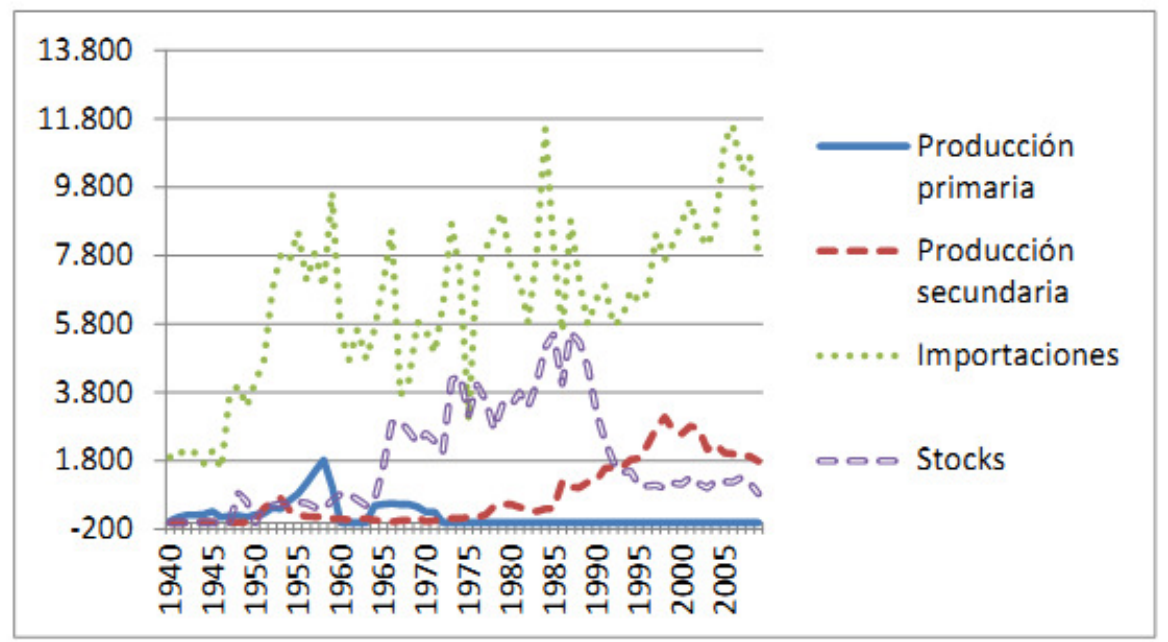

Fuente: U.S. Geological Survey.

Por último, hay algunos datos de la Organizacion para Cooperación para el Desarrollo Económico (OCDE) que merecen ser comentados. Abajo se muestra un cuadro con la autonomía material de los Estados Unidos entre 1980 y 2005. 10

10. El cuadro puede ser encontrado en: http://www.oecd.org/document/0,3746,en_2649_201185_46462759_1_1_1_1,00.html 
Cuadro 1. Autonomia Material Doméstica (Extracción Doméstica/Consumo Doméstico) por categoría material, 1980-2005. En toneladas.

\begin{tabular}{lcccc} 
EEUU & 1980 & 1990 & 2000 & 2005 * \\
$\quad$ Alimentación & 1,19 & 1,14 & 1,14 & 1,12 \\
Madera & 1,01 & 1,01 & 0,94 & 0,94 \\
Min. de construcción & 0,99 & 0,99 & 0,98 & 0,97 \\
Min. Industriales & 1,06 & 1,03 & 0,85 & 0,67 \\
Metales & 0,86 & 0,92 & 0,87 & 0,87 \\
Combustibles fósiles & 0,87 & 0,86 & 0,76 & 0,63 \\
Total & 0,96 & 0,96 & 0,91 & 0,85 \\
\hline
\end{tabular}

Fuente: OCDE/Material Resources Tables. ${ }^{*}$ Previsión.

Ésta (autonomia material) es entendida como la relación entre extracción interna y consumo interno, en tonelaje, para el total de bienes materiales en el país, incluyendo energía. De hecho, los Estados Unidos son exportadores líquidos de alimentos y tienen una buena autonomia material en maderas. En un mundo donde la energía natural del sol va a crecer cada vez más, la capacidad de producir árboles es importante, así como la extensión de tierras suficientes para todo tipo de plantas que capten la luz solar. Por otro lado, la autonomia mineral de los Estados Unidos para fines industriales es relativamente baja, con 67\% previstos para 2005, lo mismo se dando con el crudo, con una importación de casi $40 \%$ del total utilizado.

El gráfico abajo permite una mirada general última. El muestra la relación entre el consumo doméstico material con el PBI y la población, utilizando los datos de PBI del Bureau of Economic Analysis y los datos de OCDE sobre extracción doméstica total.

Gráfico 13. EEUU. Relación entre consumo doméstico material y Producto Bruto Interno y entre consumo material doméstico y habitantes. Población en número de personas, extracción doméstica en 1.000.000 toneladas y PBI miles de millones de dólares.

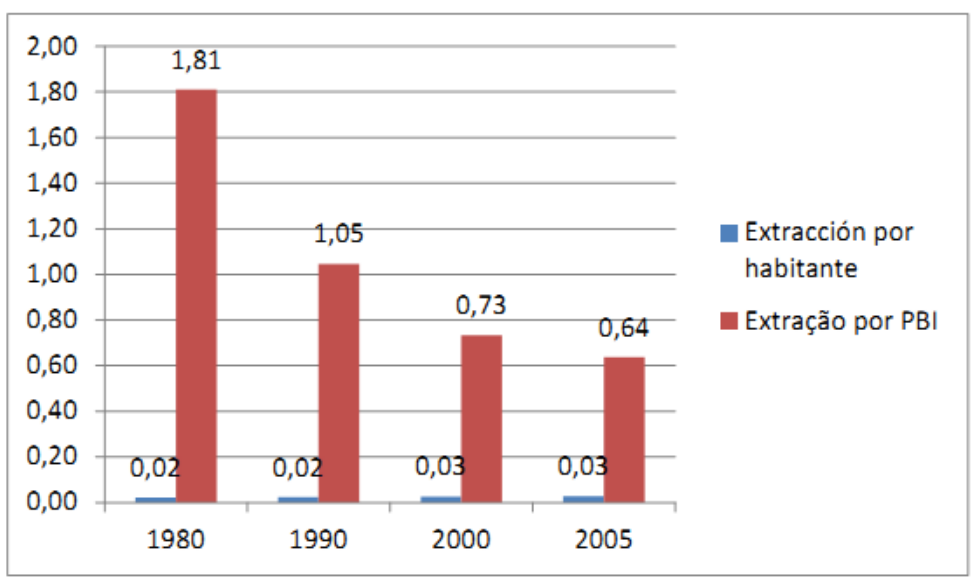

Fuente: OCDE/Material Resources Tables y BEA.

Igual que el consumo energético per capita, el consumo material total en los Estados Unidos (materias primas y consumo energético, incluyendo la extracción de energías fósiles) no 
decayó. Decayó, sí, la relación entre el consumo doméstico de materiales y el PBI, al igual que la relación entre consumo energético y PBI. Pero no disminuyó, sino que se elevó, la relación entre el consumo material total en la economía, y el número de habitantes.

Por ende, una salvedad. Abajo el último cuadro muestra una relación decreciente entre el uso de algunos metales y el número de habitantes, diferentemente de la utilización de crudo 0 carbón. Es decir, el consumo final de materiales per capita puede variar de producto a producto, y la tendencia señalada arriba es solamente general, admitiendo excepciones. Mientras que el consumo de algunos metales tiene, de hecho, tendencia para caída, el consumo de crudo y carbón, así como otros, tiene o tendencia para elevación o para estabilización. Y son estos tipos de consumo final que no presentan variación para bajo que hacen con que la tendencia general de extracción y consumo doméstico sean crecientes o por lo menos no caigan. Esto no significa, sin embargo, que el consumo de metales tenga trayectoria declinante, como se ve arriba. Significa solamente que la relación del consumo con el número de habitantes tiende a bajar para algunos productos, como los metales abajo vistos en el cuadro.

Cuadro 2. Consumo final (importaciones más producción doméstica) dividido por habitantes. 1970-2008. En toneladas métricas para metales; carbón en millones de toneladas y crudo en millares de barriles por día. Población en millones.

\begin{tabular}{rrrrrrrr} 
& \multicolumn{2}{c}{ Silicio } & \multicolumn{2}{c}{ Carbón } & \multicolumn{2}{l}{ Níquel } & \multicolumn{2}{l}{ Cobre } & \multicolumn{2}{c}{ Cobalto } & \multicolumn{2}{c}{ Crudo } \\
1970 & 2,01 & 116 & 0,75 & 8,28 & 0,03 & 0,070 & 0,002 \\
1975 & 1,92 & 110 & 0,72 & 7,89 & 0,03 & 0,070 & 0,002 \\
1980 & 1,82 & 104 & 0,68 & 7,48 & 0,03 & 0,070 & 0,003 \\
1985 & 1,74 & 100 & 0,65 & 7,15 & 0,02 & 0,060 & 0,003 \\
1990 & 1,65 & 95 & 0,62 & 6,79 & 0,02 & 0,060 & 0,003 \\
1995 & 1,55 & 89 & 0,58 & 6,38 & 0,02 & 0,060 & 0,003 \\
2000 & 1,46 & 84 & 0,55 & 6,03 & 0,02 & 0,060 & 0,003 \\
2005 & 1,40 & 80 & 0,52 & 5,75 & 0,02 & 0,060 & 0,003 \\
2006 & 1,38 & 79 & 0,52 & 5,70 & 0,02 & 0,060 & 0,003 \\
2007 & 1,37 & 79 & 0,51 & 5,64 & 0,02 & 0,060 & 0,003 \\
2008 & 1,36 & 78 & 0,51 & 5,59 & 0,02 & 0,060 & 0,003 \\
\hline
\end{tabular}

Fuente: U.S. Geological Survey para metales; para crudo y carbon, U.S. Energy Information Administration, Annual Energy Review, 2009.

La tendencia decreciente para el consumo per capita de muchos metales extraídos 0 importados, que aparentemente contradice los datos de la OCDE, tiene una explicación. Esta reside en la caída de la producción industrial de los Estados Unidos a lo largo de los años, y la elevación de las importaciones de bienes industriales. El cuadro de arriba, con datos fornecidos pelo U.S. Geological Survey, no informa la cantidad de metales en los Estados Unidos 
incorporados en los productos importados. Informa solamente los metales importados in natura o el consumo para producción doméstica, pero no computa la cantidad material ya incorporada en los productos terminados en otras naciones y comprados por el país. Por otro lado, como la elevación de las importaciones de bienes manufacturados va acompañada por la disminución de la producción industrial en el país, la propia extracción interna e importación tienen tendencia para caída. Esto no significa que el consumo material total per capita haya disminuido consumo material expresado por la suma de extracción interna, importaciones in natura e metales incorporados en las importaciones.

Los gráficos abajo expresan la participación de las manufacturas en el PBI de los Estados Unidos y la participación (1) las exportaciones totales (bienes y servicios) y el total de rentas por cobrar del resto del mundo y la (2) relación entre la remuneración de propiedad por cobrar del resto del mundo y el total de rentas por cobrar del resto del mundo.

Gráfico 14. EEUU. Sector manufacturero y finanzas en el PBI. En miles de millones de dólares. 1987-2010.

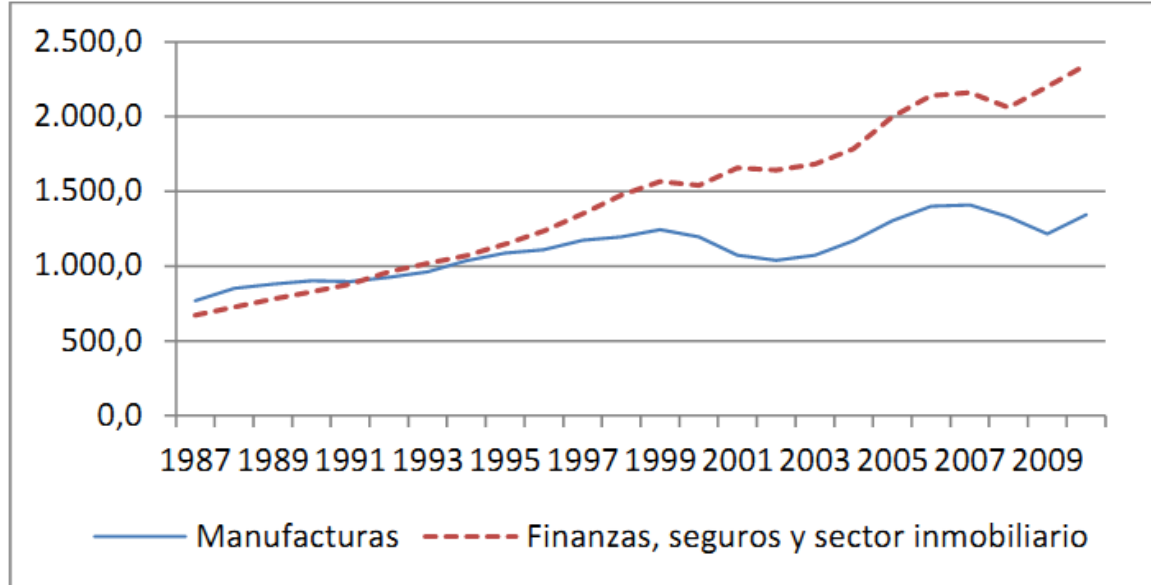

Fuente: BEA.

Los Estados Unidos producen menos manufacturas internamente y exportan relativamente menos, pero elevan a lo largo del tiempo las rentas de propiedad cobradas del mundo. Estas rentas son ganancias de corporaciones y bancos en el exterior, mayoritariamente. Su participación en los mercados del mundo les permite producir y exportar menos manufacturas y mantener el consumo material per capita. La riqueza material de su territorio y el avanzo de otros sectores cuya demanda interna se eleva - casas, principalmente - permite al consumo energético y material continuar a crecer, igualmente. Riqueza material natural y participación asegurada de sus corporaciones en el mundo son elementos cruciales para mantener la riqueza doméstica. 
Gráfico 15. EEUU. Relación entre (1) las exportaciones totales (bienes y servicios) y el total de rentas por cobrar del resto del mundo y (2) relación entre la remuneración de propiedad por cobrar del resto del mundo y el total de rentas por cobrar del resto del mundo. En miles de millones de dólares. 1969-2010.

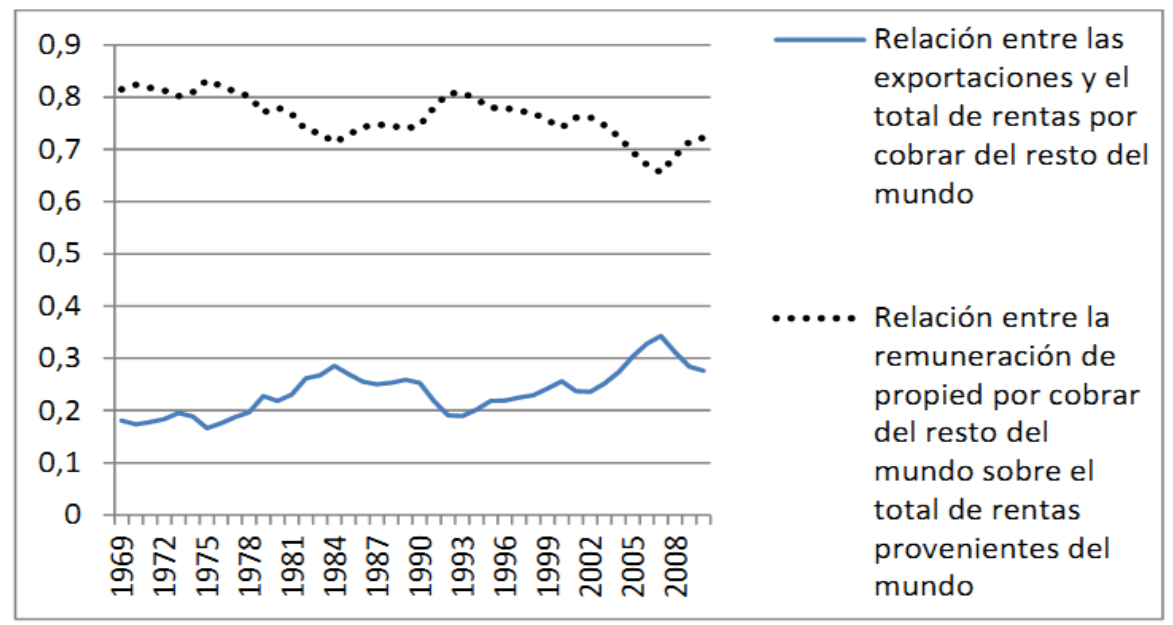

Fuente: BEA.

\section{Conclusiones}

Cuanto a la relación entre energía y materias primas consumidas a lo largo del tiempo para los Estados Unidos, hay una disparidad entre valores en términos de personas y dinero. Un análisis solamente hecho a partir del PBI mostrará una performance muy positiva de la economía norteamericana en lo que se refiere al consumo de energía y materiales por unidade monetaria en el transcurrir del tiempo. Pero un análisis por individuo, sea de consumo energético, sea material, muestra otra relación. La generación contemporánea de estadunidenses, considerada globalmente (recordándose que acá no se hace un análisis de la división interna del acceso a la riqueza), tiene un mayor acceso a bienes materiales y energéticos que sus antepasados, hecho que trae consecuencias importantes en un ambiente de recursos agotables. Las conclusiones de este trabajo son:

1) El consumo de energía y materias primas, entendidos sea como producción sea como importación, presenta crecimiento absoluto para el país; los stocks presentan decrecimiento absoluto sin perspectivas futuras de nuevas fuentes encontradas hasta la fecha;

2) Si considerada la relación volumen físico/habitante (sin evaluar los patrones de distribución), la economía norte-americana no presenta una mejora significativa del consumo de energías; 
3) Considerada la relación volumen físico/habitante, los habitantes de los Estados Unidos presentan hoy, conjuntamente (es decir, nuevamente sin evaluar los patrones de distribución), mayor consumo de materiales y energía per capita; esta relación no es verdadera para muchos metales, pero es para crudo y carbón y otros, con lo cual la media es creciente;

Así, en general la economía norteamericana no parece estar "desmaterializándose", hecho que por cierto sería una defensa del actual modo de vida. La economía no está presentando un menor consumo energético ni material por habitante. Si recordamos que la extracción de materias primas y energía siguen un camino constante, asi como sus fuentes y stocks siguen disminuyendo - por lo menos para los no reciclables - no se puede decir que el proceso acumulativo está "substituyendo" materias primas por otros productos a punto de impedir que la elevación de energía per capita y consumo material per capita elévense. Y de hecho, ¿como podría hacerlo? ¿No serían los propios sustitutos oriundos de alguna materia prima? ¿No implicaría la sustitución de un material por otro la elevación de su demanda?

La rápida elevación de la productividad y conocimientos tecnológicos no pueden asegurar un grado de "substitución" de factores que impida la depleción de los recursos de manera global. La aparente relación de mayor productividad del PBI con relación a los datos materiales resulta ser engañadora. Ella se explica tanto por el crecimiento de la inflación, como por el incremento de la productividad individual de los bienes, como por el crecimiento de las finanzas. Pero una relación física entre cantidades e individuos para el problema acá abordado muestra que los estadunidenses están consumiendo lo mismo o más cantidad de energía y materias primas que en pasado.

Afirma Lori Wagner, técnica estadunidense del propio U.S. Department of Interior and U.S. Geological Survey:

"The flows of materials generated in the world economy significantly affects peoples lives and the global environment. As population increases and people all over the world strive for a rich material life, the world is altered, wastes are generated, and the landscape is modified at a scale that is unprecedented. In order to meet the people's future material needs, resources must be used wisely and impacts to the environment need to be minimized. There are many steps that can be taken, and many that have already been taken, to continue satisfying society's material needs and desires. It is no easy feat to supply society's needs and desires without causing some damage to something somewhere. Building a road displaces native animals that inhabit the land. Building a dam changes fish habitats. Building a house means cutting down trees. Certain resources are required and always will be required. The challenge, then, is to find ways to satisfy society's needs sensibly, with an eye toward balancing material 
needs with their potential impact on the world's life-support systems and with the environmental values society holds." 11

Igualmente, el análisis de este artículo sugiere que el problema ambiental y social reside mucho más en la expansión absoluta de la producción - teniendo en cuenta que su organización industrial excluye una división más ecuánime de las horas de trabajo entre los individuos - que en cuestiones meramente técnicas, como defiende la lectura basada en la obra de Joseph Schumpeter. El capitalismo puede solucionar en el corto plazo muchos de los problemas técnicos de la producción y del consumo, tales como la substitución del crudo por la energía eléctrica o bienes materiales por substitutos sintéticos. Los substitutos sintéticos vienen de otras materias primas, como el crudo, mientras que la energía se puede obtener de los vientos y el uranio. Pero la deficiencia es de otra naturaleza.

Tiempo y estoques limitados son decisivos. En el largo plazo, con estoques disminuyendo cada vez más rápidamente, se torna cada vez más complejo substituir un material por otro. La mirada microeconómica es insuficiente, porque no abarca el todo. La lógica privada es la de la expansión absoluta de las ventas. Esta expansión absoluta del consumo, en gran parte innecesario, anula los resultados relativos al ahorro de energía y materiales e impone una carga de substituciones que no es materialmente factible, con resultados no previstos para las tentativas sucesivas de continuar cualquier inversión sobre una nueva base. Esto explica porque la cantidades absolutas continúan elevándose.

Por ejemplo, un individuo común viviendo en los Estados Unidos hoy tiene a su disposición un modelo de auto eléctrico, pero como ahora compra dos, porque los autos se baratean (en parte porque su precio no contabiliza la escasez futura), su utilización individual de energía y materia se mantiene o se eleva. Así, otros problemas de escasez de materia prima surgen, como observa correctamente la técnica arriba mencionada, Lori A. Wagner investigadora honesta de los Estados Unidos. Los ejemplos son fácilmente multiplicables con las computadoras, teléfonos, ropas etc. El futuro tiene camino no ergódico en una economía que intenta crecientemente substituir un bien por otro 0 una fuente energética por otra sin preguntarse sobre la viabilidad general de este camino, como apuntaló Nicholas Georgescu. Es decir, de difícil previsión. Para citar una vez más Lori Wagner, à la pregunta “ ¿Son los autos eléctricos la solución?", ella contesta que...

11 "U.S. Geological Survey, Materials in the Economy Material Flows, Scarcity, and the Environment", p. 28. 


\begin{abstract}
"There are several factors that affect this pollution tradeoff. It may be easier to control pollution at a power plant than from individual vehicles. Power plants often are located outside major centers of urban air pollution, and finally, while only a fraction of today's power plants use renewable resources (biomass, wind, geothermal, or solar power), electricity can be produced from these clean sources of energy. Potential health or safety risks associated with widespread electric vehicle use have not yet been fully evaluated. Many vehicle batteries contain toxic elements or produce toxic emissions, which could make battery production, transport, use, and disposal a significant solid waste issue. The United States must consider how to safely dispose of or recycle these batteries. What about hybrid electric vehicles? Hybrid electric vehicles have batteries to provide electric power but are also equipped with a small internal combustion engine (usually powered by gasoline). The engine provides a power boost and/or can be used to recharge the batteries, as pure electrics today simply cannot achieve the range, performance, or convenience of a modern gasoline car. Unfortunately, the extra engine substantially increases pollution from the vehicle, erasing many of the air quality benefits of pure electric vehicles." ${ }^{12}$
\end{abstract}

Como se ha dicho, estos problemas pueden ser multiplicados para cada bien que se intenta "substituir". La tesis de la viabilidad de la "substitución" de Solow y otros parece de difícil defensa. La rapidez con que los estoques de materias primas y fuentes de energía disminuyen y la velocidad con que las emisiones de detritos se dan - no acá mencionados - sugiere que los caminos interpretativos de Georgescu y Robinson parecen más adecuados. Incluso una economía que puede presentar una variedad grande de inventos técnicos - y no hay razones para creer que no fue asi con los Estados Unidos en el período analizado (todo lo contrario!) no parece ser capaz de detener un rápido avanzo global sobre los recursos y sobre el estoque limpio de aire, suelo y agua del medio ambiente. La elevación de las técnicas está asociada con más y no menos crecimiento.

Nadie que defienda la actual estructura social tal cual la de los Estados Unidos puede contestar las críticas de las teorías sociales y económicas que defienden otra organización de la sociedad con base sea en la crítica del desempleo, de la mala distribución y del agotamiento de los recursos. La teoría neoclásica está particularmente atrapada por insistir en el primado de la lógica privada de decisión de las inversiones, en una realidad en la cual cada vez más las decisiones particulares implican impactos colectivos. Ninguna de las vertientes de la economía liberal critica la racionalidad de las inversiones en un aparato productivo cuyo fin es, de hecho, en la mayoría de los casos, dispensable - incluyendo ahí todas las inversiones que los Estados Unidos realizan en el complejo industrial-militar.

El economista neoclásico puede argumentar que la disminución del consumo y de cualquier inversión conducirá a un mayor desempleo. Pero no puede contestar por la racionalidad de un plan que llevaría a disminuir las horas de trabajo para todos los empleados,

12 "U.S. Geological Survey, Materials in the Economy Material Flows, Scarcity, and the Environment", p. 23. 
en un sistema colectivo de organización y distribución, a fin de que los desocupados pudieran igualmente acceder al trabajo. Asi, el aparato teórico de la economía neoclásica no puede permitir soluciones para el desempleo y el problema ambiental de una economía que privatiza la toma de decisiones de la inversión: solamente una alteración de las decisiones de inversión privada podría conducir al pleno empleo, y a una utilización ambiental satisfactoria de los recursos ambientales. Y forjaría un ambiente social dentro del cual el nivel de vida disminuiría para todos, pero se elevaría su calidad.

El gobierno de los Estados Unidos tiene una tarea dupla: introducir modificaciones en la utilización de la base energética, y al mismo tiempo, manipular la política económica para que la economía vuelva a presentar un crecimiento económico. Pero hay un doble problema en la administración del país. Éste atraviesa una crisis económica de amplia proporción, pero presenta un consumo de materiales y energía absolutamente y relativamente muy grande. Particularmente, las previsiones relativas a la reserva de petróleo en territorio de los Estados Unidos indican que éste irá a acabarse para 2067.

El gobierno de los Estados Unidos sólo apunta en su informe al problema de la escasez energética y no al de la escasez de los recursos naturales materiales. Pero el problema de todo modelo de acumulación no es apenas energético. Como se ve, es material y energético. Las fuentes de energía actualmente existentes tal vez puedan ser substituidas en un futuro cercano, pero no pasa lo mismo con la base material que sustenta la actividad económica. Estas se desgatan y el reciclaje tiene límites. Todo substituto tiene una fuente material "natural", y toda fuente material "natural" es escasa en el longo prazo. Por esto no es legítimo contestar que "a largo plazo estaremos muertos", y que por lo tanto el problema de la escasez material puede ser postergado. Las consecuencias para el mundo y la sociedad contemporánea del modelo de acumulación capitalista norteamericano presentan hoy sus consecuencias, particularmente cuanto al problema del petróleo, porque vivemos hoy el resultado del "largo plazo" que empezó antes.

Con una organización y distribución más equitativa de los puestos y el tiempo de trabajo, podría haber un nivel de inversión más bajo y las fuentes de energía podrían asumir un carácter totalmente renovable. Pero, ¿cómo hacer con los stocks de hierro, agua, tierra y otros bienes noreproducibles? ¿Podría la economía futura "desmaterializarse" a punto tal de no depender más de la producción física? ¿Cómo podría lograrlo, si la base material de la sociedad es la propia condición de la división desigual del producto físico social?

La economía de los Estados Unidos no está "desmaterializada". Está dependiente del crudo internacional y una serie de otros tipos de materiales, y asiste a un gran consumo interno 
de bienes no renovables como el carbón y el gas. A partir de las series históricas analizadas y sus interrelaciones, puede deducirse que la escasez futura engendrará muchas soluciones técnicas de substituciones parciales, pero la escasez absoluta tendrá a elevarse. El aparato militar estadunidense y la presencia de sus corporaciones en el globo serán entonces aún más necesarios para (1) el acceso directo a las materias primas y energía o (2) para financiar las importaciones a partir de los flujos las rentas de propiedad.

\section{Fuentes de datos}

1. Bureau of Economic Analysis (BEA)

2. Organización para Cooperación para el Desarrollo Económico (OCDE)

3. U.S. Geological Survey

4. U.S. Energy Information Administration

5. Gobierno de los Estados Unidos (Economic Report of the President)

\section{Bibliografía}

1. Alier, Joan Martinez and Schlüpmann, Klaus. La ecología y la economía. Mexico City: Fondo de Cultura Económica, 1993.

2. Alier, Joan Martinez. The Environmentalism of the poor: a study of ecological conflicts and valuation. London: Edward Elgar, 2002.

3. e Jusmet, Jordi Roca. Economía ecológica y política ambiental. Mexico City: Fondo de Cultura Económica, 2003.

4. Georgescu-Roegen, Nicholas. The Entropy Law and the Economic Process. New York: Harvard University Press, 1971.

5. . "The Entropy Law and the Economic Process in Retrospect". Eastern Economic Journal, V. XII, No.1, January-March, 1986.

6. Gobierno de los Estados Unidos. Economic Report of the President, 2010. Washington: U.S. Printing Office, 2011.

7. Gowdy, John and Daly, Herman E.. "The Evolution of Georgescu-Roegen's Bioeconomics". Review of Social Economy. Vol. LVI. No. 2. Summer, 1998.

8. K. Marx, Capital, V. III, The Process of capitalist production as a whole. Moscow: Foreign Languages Publishing House, 1962.

9. Michael Löwy. "Écosocialisme et Plannification Democratique". 2009. Disponible en www.lafederation.org /. 
10. Mayumi, Kozo e Gowdy, John. Bioeconomics and Sustainability - Essays in Honour of Nicholas Georgescu-Roegen. Cheltenham (UK): Edward Elgar. 1999.

11. OCDE, Material Resources Table, 2009. Disponible en www.oecd.org/.

12. Robinson, Joan. "The second crisis of economic theory." In: American Economic Review, v.62, n. 1/2, March, 1972.

13. Further Contributions to Modern Economics. Oxford: Basic Blackwell, 1980.

14. Solow, Robert. "The economics of resources or the resources of economics." American Economic Review. May, 1974.

15. Departamento de Energía de los EEUU. (U.S. Energy Information Administration). Annual Energy Review, 2009. Washington: 2010.

16. Wagner, Lori. Materials in the Economy-Material Flows, Scarcity, and the Environment . U.S. Geological Survey Circular 1221. 2002. Disponible en:

http://geology.cr.usgs.gov/pub//

Artigo recebido em: 12/08/2011

Aprovado em: 27/11/2011 